\title{
Genital manifestations of tropical diseases
}

\section{J Richens}

Sex Transm Infect 2004;80:12-17. doi: 10.1136/sti.2003.004093

Genital symptoms in tropical countries and among returned travellers can arise from a variety of bacterial, protozoal, and helminthic infections which are not usually sexually transmitted. The symptoms may mimic classic sexually transmitted infections (STIs) by producing ulceration (for example, amoebiasis, leishmaniasis), wartlike lesions (schistosomiasis), or lesions of the upper genital tract (epididymo-orchitis caused by tuberculosis, leprosy, and brucellosis; salpingitis as a result of tuberculosis, amoebiasis, and schistosomiasis). A variety of other genital symptoms less suggestive of STI are also seen in tropical countries. These include hydrocele (seen with filariasis), which can be no less stigmatising than STI, haemospermia (seen with schistosomiasis), and hypogonadism (which may occur in lepromatous leprosy). This article deals in turn with genital manifestations of filariasis, schistosomiasis, amoebiasis, leishmaniasis, tuberculosis and leprosy and gives clinical presentation, diagnosis, and treatment.

Series editor: David Lewis

Correspondence to: J Richens, Department of Sexually Transmitted Diseases, University College London, The Mortimer Market Centre, Mortimer Market, London WCIE 6AU, UK; jrichens@gum.ucl.ac.uk

Accepted for publication 25 July 2003
$\mathrm{T}$ hs review concentrates on six infections that cause significant genital morbidity in tropical countries-namely, Bancroftian filariasis, schistosomiasis (especially infection due to Schistosoma haematobium) amoebiasis, leishmaniasis, tuberculosis, and leprosy (mostly the lepromatous form). The main emphasis is on clinical features. Investigative methods pertinent to genital disease are covered and the main aspects of therapy are mentioned in addition to specific advice about genital complications. For more detail on the investigation and treatment of these diseases, particularly standard therapies for tuberculosis and leprosy, readers should consult standard texts. A miscellany of other infectious and non-infectious conditions causing genital morbidity in the tropics is mentioned in the final section.

\section{METHODS}

Two earlier reviews of this subject were taken as a starting point. ${ }^{12}$ These suggested that filariasis, schistosomiasis, amoebiasis, and mycobacterial infections were the diseases that warranted most attention. Tuberculosis is included because of the rising incidence of this infection in the tropics and relatively high incidence of extragenital disease that has long been observed in many parts of the tropics. The author found that the most reliable strategy for retrieving relevant articles from Medline that described genital manifestations of these infections was to com- bine medical subject headings for individual infections with the headings genital diseases, male and genital diseases, female, exploding the latter terms to include all their subheadings. Genital tuberculosis cases are conveniently indexed in Medline under the heading tuberculosis, male genital, and tuberculosis, female genital. All abstracts were screened and the full text of individual articles read for all reviews and case series. References in articles were examined for to check for further pertinent articles. Individual case reports were not read unless they emphasised special features not previously reported or included useful reviews of the literature. The references selected are those that reflect the greatest experience in a specific area or which describe important new developments or observations.

\section{FILARIASIS}

Two species of filarial worm cause genital disease in humans. Much the most important is Wuchereria bancroftii, which accounts for $90 \%$ of filarial infections and is estimated to infect 100 million people in the tropics. Of these, $40 \%$ have disfiguring manifestations and 27 million men are estimated to suffer from genital deformity. ${ }^{3}$ Genital morbidity in women is much rarer. ${ }^{4}$ Bancroftian (lymphatic) filariasis has been ranked the second leading cause of disability in the world by the World Health Organization (WHO) and ranked second to HIV in Haiti as a public health issue for the community. ${ }^{5}$ Onchocerciasis, caused by Onchocerca volvulus, is remembered by most students of tropical medicine for an unusual complication known as the "hanging groin," caused by a combination of inguinal adenopathy and skin atrophy that results in hanging folds of skin containing lymph nodes. Minor deformities of scrotal skin may also develop. Recent surveys in endemic areas reported hanging groin in $14 \%$ in Nigeria $^{6}$ and pendular scrotum in $19 \%$ in Ethiopia. ${ }^{7}$ The remainder of this section will deal with the more important Bancroftian filariasis.

Filariasis occurs in Africa, Asia, South America, the Caribbean, and the Pacific. Transmission is through mosquitoes that transmit larvae that develop into adult worms in the human host. Recent studies have shown it often possible to identify nests of adults worms by ultrasound. The worms display a characteristic movement termed the "filarial dance." ${ }^{\prime 8}$ In men the lymphatics of the spermatic cord are a favoured location. The adult worms release microfilaria into the blood in large numbers in the early part of the night, thus making detection of microfilaria in a night blood sample a convenient tool for diagnosis. The presence of 
Table 1 Male genital manifestations of infection with Wuchereria bancroftii

\begin{tabular}{ll}
\hline Manifestations & Comments \\
\hline $\begin{array}{l}\text { Lymphangiectasia of lymphatics round the } \\
\text { spermatic cords }\end{array}$ & $\begin{array}{l}\text { Earliest sign of infection. Detectable by ultrasound in } 80 \% \\
\text { of men found to have microfilaraemia. Initially } \\
\text { asymptomatic } \\
\text { Develops when adult worms die naturally or as a result of } \\
\text { therapy } \\
\text { Detectable in up to } 40 \% \text { of males in areas hyperendemic } \\
\text { for filariasis }\end{array}$ \\
Chronic hydrocele & $\begin{array}{l}\text { Collection of chyle that forms when a lymphatic ruptures } \\
\text { into a hydrocele } \\
\text { Superficial scrotal lymphangiomatosis which may ooze } \\
\text { chyle through deformed scrotal skin }\end{array}$ \\
Chylocele & $\begin{array}{l}\text { May be triggered by death of adult worms or } \\
\text { superimposed bacterial infection. Tender scrotal nodules or } \\
\text { irregularity of spermatic cords may be felt } \\
\text { Late hypertrophy and fibrosis that results from repeated } \\
\text { bacterial infections. Urine flow not affected } \\
\text { Develops acutely when adult worms die. Also triggered by } \\
\text { bacterial infections in genitalia or legs. Occasionally } \\
\text { filarial abscess develops }\end{array}$ \\
Elephantiasis of scrotum (fig 1) &
\end{tabular}

infection leads initially to asymptomatic lymphangectasia. ${ }^{9}$ The death of adult worms provokes acute inflammation and lymphatic dysfunction and the late effects of disease result from superimposed bacterial infection in areas of lymphatic dysfunction. The specific clinical features that result from these processes in the genital area are described in table 1.

The psychosocial impact of filariasis (table 2) has been highlighted in recent research carried out in Brazil and Nigeria.

The diagnosis is usually made by demonstrating the presence of microfilaria in peripheral night blood samples, for which a variety of techniques are available. ${ }^{12}$ Adult worms within the scrotum can be demonstrated by ultrasound with a 7.5 MHz transducer. ${ }^{8}$ Demonstrating microfilaria becomes more difficult in late stage disease. Antibody and antigen detection techniques are available in special centres. One study conducted in an endemic area showed that $37 \%$ of men initially reported as amicrofilaraemic in a $60 \mu \mathrm{l}$ capillary sample could be shown to have filariasis by testing larger blood volumes or by scrotal ultrasound for adult worms. ${ }^{13}$

Diethylcarbamazine (DEC) in three divided doses of $6 \mathrm{mg} /$ $\mathrm{kg}$ /day for 12 days kills adults and microfilariae. The death of worms can provoke quite intense systemic and local reactions but does not generally require withdrawal of treatment. DEC treatment alone does not produce regression of hydroceles. ${ }^{14}$ Ivermectin is effective only against microfilariae and has an important role in control programmes. Surgery for scrotal elephantiasis produces much more satisfactory results than surgery for elephantiasis of the legs. ${ }^{15}$ Studies from Ghana have shown that surgery for hydrocele brings marked

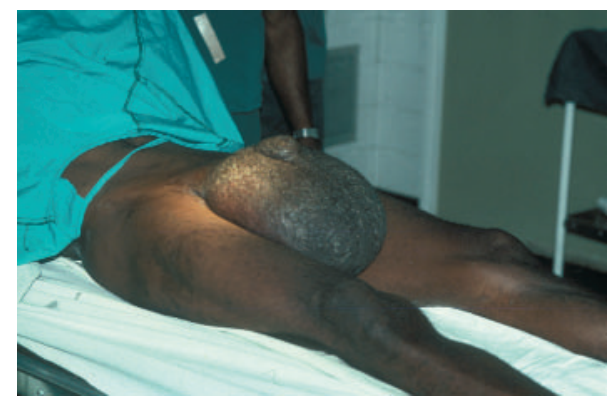

Figure 1 Scrotal elephantiasis from Bancroftian filariasis. Patient being prepared for surgery in Papua New Guinea. improvements in physical and social wellbeing, increases capacity for work and community participation, and merits much greater attention than it has so far received in endemic areas. ${ }^{11}$ Aspiration followed by sclerotherapy with tetracycline offers a useful alternative method for dealing with thin walled hydroceles. ${ }^{16}$ Good skin care and prompt treatment of bacterial skin infections is important to stop the disease progressing.

\section{SCHISTOSOMIASIS}

Schistosomiasis comprises a group of helminth infections characterised principally by extensive egg shedding into the bladder (mainly Schistosoma haematobium) or rectum (mainly $S$ mansoni and $S$ japonicum) by adults worms residing in nearby venous plexuses. The inflammatory reaction to soluble egg antigens released through pores in the walls of eggs that become lodged in tissue produces a wide array of symptoms, notably haematuria and bloody diarrhoea, and sequelae such as periportal fibrosis. Genital complications of schistosomiasis are less well known but may have important implications for control of cervical cancer ${ }^{17}$ and HIV in women. ${ }^{18}$ Both sexes may develop genital complications but, in contrast with filariasis, the genital morbidity is much greater in women than men. Schistosomiasis is acquired by exposure to water colonised by various species of snail which act as intermediate hosts and which release into the water motile miracidia capable of penetrating human skin. The disease is believed to infect 193 million people in the tropics, with $85 \%$ of infections occurring in Africa. Each of the Schistosoma species that infects humans has a specific distribution related to local snail ecology.

Table 2 Social impact of genital filariasis reported by Dreyer et $a^{\beta}$ and Ahorlu et $a^{11}$

Loss of physical intimacy

Difficulty in finding marriage partners

Conspiracy of silence, embarrassment, ridicule, loss of self esteem,

reduced social interaction

Reduced work capacity

Loss of inheritance

Suicidal ideation

Dyspareunia in female partners resulting from penile deformity of infected male partners 
Table 3 Clinical features of female genital schistosomiasis

\begin{tabular}{|c|c|}
\hline Site & Clinical manifestations \\
\hline Fallopian tubes & $\begin{array}{l}\text { Infection can simulate pelvic inflammatory } \\
\text { disease and lead to infertility }{ }^{24} \text { and ectopic } \\
\text { pregnancy }^{25}\end{array}$ \\
\hline Uterus & Disturbed menstruation, fetal loss \\
\hline Placenta & Second trimester abortion \\
\hline Cervix & $\begin{array}{l}\text { Ulceration, growths, sandy patches, } \\
\text { cervicitis, discharge, post-coital bleeding, } \\
\text { dyspareunia }\end{array}$ \\
\hline Vagina & $\begin{array}{l}\text { Growths, ulcers, sandy patches, recto- } \\
\text { vaginal and vesico-vaginal fistulae }\end{array}$ \\
\hline Vulva & $\begin{array}{l}\text { Swelling, ulceration, wart-like growths, } \\
\text { pruritus, clitoral hypertrophy }\end{array}$ \\
\hline
\end{tabular}

\section{Female genital schistosomiasis (FGS)}

Poggensee et al have summarised current knowledge about the clinical features of $\mathrm{FGS}^{17}$ (table 3 ) and have conducted excellent field studies. ${ }^{19} S$ haematobium is the predominant worm but $S$ mansoni is also capable of migrating sufficiently to produce genital lesions. Feldmeier et al have estimated that $6-27 \%$ of females with intestinal schistosomiasis may also develop genital lesions. ${ }^{20}$ The extent of genital morbidity arising from $S$ japonicum infection appears to be much less. ${ }^{21}$ Confusion of cervical lesions with carcinoma and of vulval lesions (fig 2) with genital warts may occur. ${ }^{22}$ "Sandy patches" of the vagina and cervix which result from subepithelial calcification of ova are especially distinctive lesions. ${ }^{23}$ It has been postulated that FGS exacerbates the effects of human papillomavirus infection, leading to swifter development and spread of cervical cancer. Many women in Africa develop cervical cancer under the age of 30 and Tanzanian studies have indicated high rates of FGS in the youngest women. Women with FGS may develop multiple mucosal lesions and this, coupled with the intensity of inflammation associated with schistosomiasis, could make FGS an even more potent co-factor for HIV transmission than sexually transmitted infections, which often cause less mucosal disruption and inflammation. ${ }^{18}$

The diagnosis is best made by the quantitative compressed biopsy technique (QCBT) which gives a better yield than histology or examination of urine specimens. ${ }^{26}$ A wet smear technique offers a means of rapid diagnosis in some cases. ${ }^{27}$ Eosinophil cationic protein (ECP) is elevated in patients with FGS and testing for the presence of ECP is being explored as a possible method of screening. ${ }^{28}$

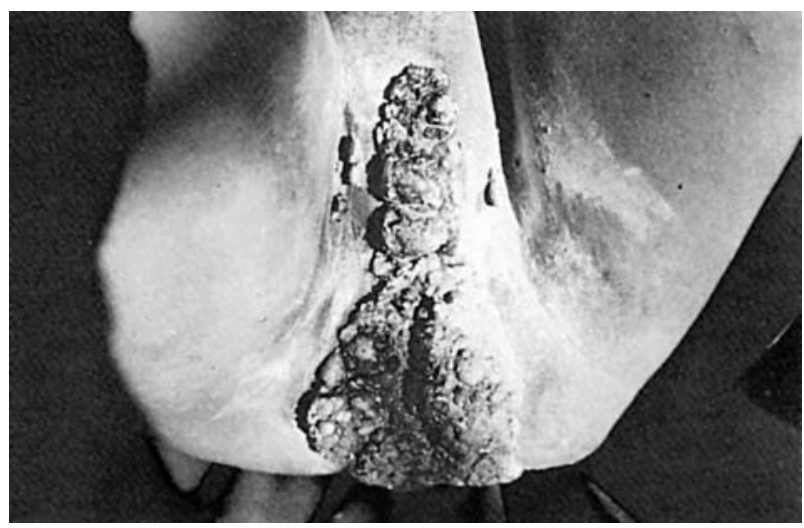

Figure 2 Genital schistosomiasis (Gilles HM. Clinical Tropical Medicine and Communicable Diseases Vol 2, Nol, 1987). Reproduced courtesy of HM Gilles and Elsevier Science Publications.
Mild disease shows signs of regression within 9 weeks of a single dose of praziquantel $40 \mathrm{mg} / \mathrm{kg}$. Where more extensive lesions are present $4-5$ doses at 48 hour intervals have been recommended. ${ }^{17}$

\section{Male genital schistosomiasis}

The ability of schistosomiasis to cause bleeding and egg deposition within semen was first clearly demonstrated by the intrepid Claude Barlow who deliberately infected himself with cercariae in 1944 and then observed the development of haemospermia and the appearance of schistosome ova in his own semen..$^{29}$ MacKenna et al reported how seven men from New Zealand attended a sexual health clinic in Christchurch complaining of either yellow discoloration (three cases), reduction in semen volume (two cases), or consistency (two cases). ${ }^{30}$ All the men had swum in Lake Malawi while travelling in Africa. Treatment with single dose praziquantel led to recovery in all cases. Other reports have described the development of haemospermia and lumpy semen in men with schistosomiasis. ${ }^{31-33}$ Calcifications of the seminal vesicles and prostate may be observed on ultrasound. ${ }^{34}$ This author was able to make a rapid diagnosis of schistosomiasis in a young adult male who attended a sexual health clinic complaining of lumpy semen after returning from work in Africa where he reported swimming in Lake Malawi. He produced a fresh specimen of semen in the clinic which confirmed his description. One of the lumpy areas was squashed under a cover slip and eggs containing wriggling larvae were shown to the patient before starting therapy. There are a small number of case reports of lesions of schistosomiasis developing within the testes (simulating carcinoma $^{35}$ or causing infarction $\left.{ }^{36}\right)$, epididymis, ${ }^{37}$ and the penis. ${ }^{38}$ Male infertility resulting from such lesions is rare. ${ }^{39}$

\section{AMOEBIASIS}

The classic effects of infection with Entamoeba histolytica are the development of a colitis that gives rise to amoebic dysentery, colitis, and liver abscess when organisms enter the portal system. E histolytica has also been reported as a cause of genital ulcer. In a review of 148 case reports of genital amoebiasis confirmed by observation of E histoloytica published between 1924 and 1997, Antony and Lopez-Po noted that $85 \%$ of reports were of genital infection in females, including infants. ${ }^{40}$ Female genital amoebiasis is characterised by a foul, bloody vaginal discharge. In one third abdominal pain was reported and $8.1 \%$ had genital ulceration, often mimicking carcinoma of cervix, although in some cases amoebiasis and carcinoma have been found together. ${ }^{41}$ Involvement of uterus ${ }^{42}$ and tubes ${ }^{43}$ has also been reported; $92 \%$ of cases were diagnosed in cervical cytology specimens and the remainder by ulcer biopsy. Eighty six per cent of cases in men presented as a painful, discharging ulcer (fig 3), again often mimicking carcinoma and the remainder with discharge or dysuria. The diagnosis in men was made by biopsy, culture, smear, or wet preparation. In addition to these methods serological tests and nucleic acid amplication tests are now available to diagnose amoebiasis. Genital amoebiasis lesions generally respond swiftly to a standard course of metronidazole treatment $(800 \mathrm{mg}$ three times daily for 5 days). Neglected cases have progressed to necrotising vulvitis requiring radical vulvectomy. ${ }^{44}$ The infection can be sexually transmitted ${ }^{45}$ and sexual partners of patients with genital amoebiasis should be examined and offered treatment.

\section{CUTANEOUS LEISHMANIASIS}

The leishmaniases are a group of diseases caused by protozoa of the Leishmania genus that affect $1-2$ million people per year between latitudes $45^{\circ}$ north and $32^{\circ}$ south. Each species 


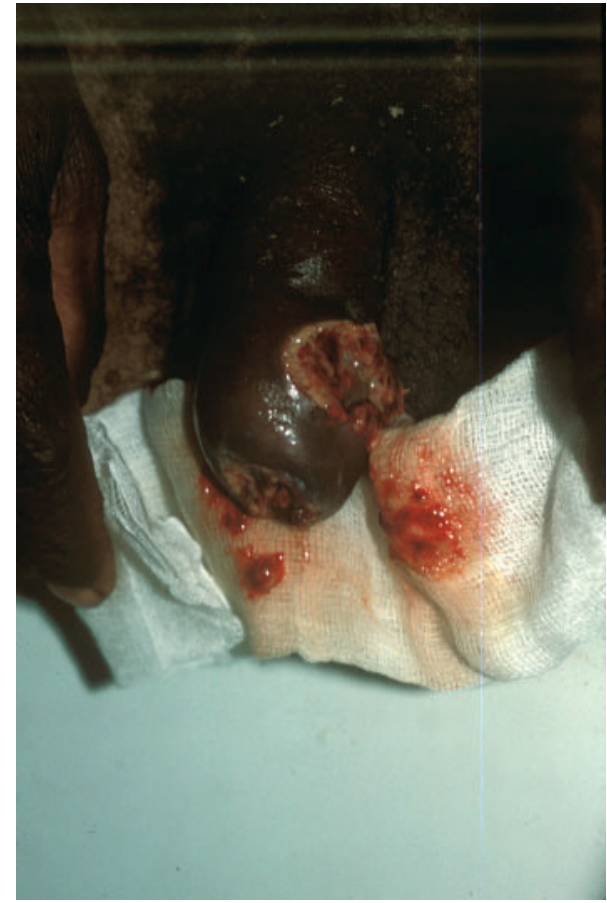

Figure 3 Genital amoebiasis: purulent, perforating ulcer of the prepuce in patient from Papua New Guinea. Rapid healing followed treatment with metronidazole.

has an animal reservoir and can be transmitted to humans by sandfly bites. Following inoculation organisms are taken up by macrophages where they are able to resist degradation. The ensuing release of cytokines and cell mediated immune response to infection leads to the development of lesions. Cutaneous leishmaniasis is usually characterised by chronic localised ulceration developing at the site of inoculation. Genital lesions (fig 4) are rare but have been described in South America among miners ${ }^{46}$ and farmers. ${ }^{47}$ One vulval lesion has been reported. ${ }^{48}$ The diagnosis is confirmed by demonstrating the presence of Leishmania amastigotes in smear or biopsy material. Culture and polymerase chain reaction methods can increase detection rates. Treatment should be undertaken with expert advice and will usually be either systemic or local pentavalent antimonial therapy depending on the the species and clinical picture. Mild cases caused by certain species such as L peruviana may resolve spontaneously.

\section{GENITAL TUBERCULOSIS}

Male genital tuberculosis

Important genital manifestations of tuberculosis in men are summarised in table 4.

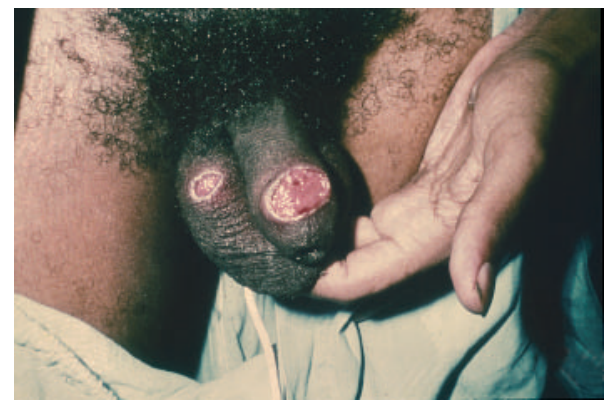

Figure 4 Cutaneous leishmaniasis of penis and scrotum.
Infection of the male genitalia is believed to originate in most cases from renal foci which shed bacteria down the ureters to the prostate, followed by canicular or lymphatic spread to the epididymis, vas, urethra, and testis. Haematogenous spread to these sites is also possible in cases of miliary infection. Sexual transmission of tuberculosis from women to men has not been recorded although sexual transmission in the opposite direction has been described. ${ }^{51}$ Cases of tuberculosis epididymitis account for most reports of male genital tuberculosis. Infection on one side is often followed the appearance of disease on the other side. Epididymitis commences with the gradual onset of swelling, followed by pain. Acute infections have occasionally been described. Tethering to scrotal skin may arise with later development of discharging scrotal fistulae. Involvement of the testis is usually a late feature. Examination shows an enlarged, irregular, nodular epididymis. Tuberculous involvement of the prostate may manifest with dysuria, frequency, haematuria, and haemospermia. Examination may reveal firm, irregular enlargement, nodularity, or soft areas of necrosis. Confirmation of the diagnosis may be made by detection of acid fast bacilli or positive cultures from urine, semen, pus, or biopsy specimens or by biopsy histology. Common additional findings include a sterile pyuria and the demonstration of focal calcification by ultrasound or radiology. All patients should be screened for the presence of pulmonary and renal lesions. Treatment is generally with conventional courses of tuberculosis chemotherapy. Surgery may be required to deal with abscesses, obstructive symptoms, or failures of chemotherapy.

\section{Female genital tuberculosis}

Primary or secondary infertility is the most common presentation. In developing countries tuberculosis may account for $5-20 \%$ of tubal infertility. ${ }^{52}$ Both tubes are likely to be affected but endometrial disease is not always present. ${ }^{53}$ Presentation with pain or abnormal bleeding occurs in postmenopausal women. ${ }^{54}$ Pelvic tuberculosis can also simulate ovarian carcinoma..$^{55}$ Culture of menstrual fluid was found more useful for diagnosis than endometrial biopsy or culture in one large South African study. ${ }^{52}$ In this study it was also noted that the chest $x$ ray was normal in $93 \%$ of women and there were no abnormal findings on examination in over $50 \%$. PCR methods have recently been found useful for diagnosis of culture negative cases. ${ }^{56}$ The prognosis for fertility following tuberculous salpingitis is poor ${ }^{57}$ and the risk of ectopic pregnancy is increased. Less common manifestations of genital tuberculosis in women are tuberculosis of the cervix, ${ }^{58}$ which can mimic carcinoma and donovanosis. Tuberculous ulceration of the vulva is rare. It presents as chronic, painful genital ulceration and may be accompanied by scarring and sinuses; 100 cases were reviewed by Pardini in $1949 .^{59}$

\section{LEPROSY}

Leprosy is a mycobacterial disease affecting about one million people in the tropics. It is largely limited to skin, nasal cavity, and peripheral nerves by the preferential growth of Mycobacterium leprae at temperatures of $27-30^{\circ} \mathrm{C}$. The scrotal contents, by virtue of their lower temperature, are susceptible to infection among patients who develop the lepromatous form of the disease and during episodes of erythema nodosum leprosum (type 2 reactions). These patients may initially experience episodes of testicular pain or swelling, even before any other manifestations are observed. ${ }^{60}$ The subsequent development of testicular atrophy, gynaecomastia, and loss of body hair are well known features of established lepromatous leprosy. Infertility and sexual dysfunction develop as the testes become small, soft, and 


\begin{tabular}{|c|c|c|}
\hline Site & Comments & Key references \\
\hline Epididymis & $\begin{array}{l}\text { Main genital site, may involve } \\
\text { both sides }\end{array}$ & Gorse and Belshe, $1985^{49}$ \\
\hline Testis & $\begin{array}{l}\text { Usually a late complication of } \\
\text { epididymal disease. Infertility may } \\
\text { ensue }\end{array}$ & \\
\hline Vas deferens & $\begin{array}{l}\text { Infection may lead to nodular or } \\
\text { pipestem thickening }\end{array}$ & \\
\hline Scrotal skin & $\begin{array}{l}\text { Tethering, loss or rugae and fistulae } \\
\text { may follow epididymal infection }\end{array}$ & \\
\hline Prostate & $\begin{array}{l}\text { Important site. Probable source of } \\
\text { epididymal disease in many cases. } \\
\text { May become irregularly enlarged. } \\
\text { Acid fast bacilli shedding in semen } \\
\text { may occur }\end{array}$ & \\
\hline Seminal vesicles & Irregular enlargement may occur & \\
\hline Urethra & $\begin{array}{l}\text { Stricture may develop in prostatic } \\
\text { portion }\end{array}$ & \\
\hline Penis & $\begin{array}{l}\text { Rare site. Destructive lesions of glans } \\
\text { possible }\end{array}$ & Lewis, $1946^{50}$ \\
\hline Inguinal lymph nodes & $\begin{array}{l}\text { Scarring and fistulae may develop. } \\
\text { May be confused with } \\
\text { lymphogranloma venereum or cat } \\
\text { scratch disease }\end{array}$ & \\
\hline
\end{tabular}

insensitive and investigation may demonstrate oligospermia or azoospermia as well as elevated levels of luteinising hormone and follicle stimulating hormone and reduced testosterone. ${ }^{61}$ Patients with tuberculoid and other forms of leprosy occasionally develop skin lesions of the penis and scrotum that might be confused with STI. ${ }^{62}{ }^{63}$ Leprosy is diagnosed by clinical findings (especially the presence of peripheral nerve thickening) supplemented by slit skin smears to look for acid fast bacilli. Most patients with leprosy are treated with multidrug regimens following the recommendations of the WHO. ${ }^{64}$

\section{MISCELLANEA}

Brucellosis is an important cause of epididymo-orchitis among cattle dealers ${ }^{65}$ and those who drink unpasteurised milk in endemic areas. Isolation of Brucella melitensis from semen and sexual transmission to female partners has been reported. ${ }^{66}$ The diagnosis is suggested by associated fever and rheumatological symptoms and may be confirmed by culture, serology, and epididymal aspiration. ${ }^{67}$ Recommended treatment for brucellosis is 6 weeks of doxycyline with 3 weeks of streptomycin. ${ }^{68}$

Physicians working in south and South East Asia will be familiar with so called semen loss syndromes, characterised by weakness, fatigue, and the conviction that this is linked to involuntary semen loss. Much has been written about this syndrome in India where it is referred to as "dhat," or, more misleadingly, prostatorrhoea. ${ }^{69}$ No organic basis has been identified and it is most easily understood in terms of cultural concepts of semen and vitality. Depression scores are elevated among patients diagnosed with dhat. ${ }^{70}$ Rather more dramatic are occasional "epidemics" of a disease known as "koro," characterised by a delusion in men that their genitalia are shrinking inwards and that they may die as a result. An outbreak in north eastern Thailand in 1976 led 200 people to attend hospital..$^{71}$

\section{REFERENCES}

1 Gilles HM. Genital manifestations of parasitic diseases. In: Osoba AO, ed. Sexually transmitted diseases in the tropics. Vol 2, Number 1. Baillière's clinical tropical medicine and communicable diseases international practice and research. London: Baillière Tindall, 1987:185-93.
2 Wyatt GB. Tropical diseases with genital manifestations. In: Arya OP, Hart CA, eds. Sexually transmitted infections and AIDS in the tropics. New York: CABI Publishing, 1998

3 Dreyer G, Norões J, Addiss D. The silent burden of sexual disability associated with lymphatic filariasis. Acta Trop 1997;63:57-60.

4 Bernhard P, Makunde RW, Magnussen P, et al. Genital manifestations and reproductive health in female residents of a Wuchereria bancrofti-endemic area in Tanzania. Trans R Soc Trop Med Hyg 2000;94:409-12.

5 Eberhard ML, Walker EM, Addiss DG, et al. A survey of knowledge, attitudes and perceptions (KAPs) of lymphatic filariasis, elephantiasis and hydrocele among residents in an endemic area in Haiti. Am J Trop Med Hyg 1996:54:229-303.

6 Nmorsi OP, Oladokun IA, Egwunyenga OA, et al. Eye lesions and orchocerciasis in a rural farm settlement in Delta state, Nigeria. Southeast Asian J Trop Med Public Health 2002;33:28-32.

7 Mengistu G, Balcha F, Britton S. Clinical presentation of onchocerciasis among indigenous and migrant farmers in Ethiopia. East Afr Med J 1999;76:635-8.

8 Amaral F, Dreyer G, Figueredo-Silva J, et al. Live adult worms detected by ultrasonography in human bancroftian filariasis. Am J Trop Med Hyg 1994;50:753.

9 Dreyer G, Norões J, Figueredo-Silva J, et al. Pathogenesis of lymphatic disease in bancroftian filariasis: a clinical perspective. Parasitol Today 2000;16:544-8.

10 Gyapong JO, Magnussen P, Binka FN. Parasitological and clinical aspects of bancroftian filariasis in Kassena-Nakana District, upper east region Ghana. Trans R Soc Trop Med Hyg 1994;88:555-7.

11 Ahorlu CK, Dunyo SK, Asamoah G, et al. Consequences of hydrocele and benefits of hydrocelectomy: a qualitative study in lymphatic filariasis endemic communities on the coast of Ghana. Acta Trop 2001;80:215-21.

12 Simonsen PE. Filariases. In: Cook GC, Zumla A, eds. Manson's tropical diseases. 21 st ed. London: WB Saunders, 2003.

13 Dreyer G, Santos A, Norões J, et al. Amicrofilaremic carriers of adult Wuchereria bancrofti. Trans R Soc Trop Med Hyg 1996;90:288-9.

14 Bernhard P, Magnussen P, Lemnge MM. A randomized, double-blind placebo-controlled study with diethylcarbamazine for the treatment of hydrocele in an area of Tanzania endemic for lymphatic filariasis. Trans $R$ Soc Trop Med Hyg 2001 ;95:534-6.

15 Ollapallil JJDA. Surgical management of elephantiasis of male genitalia $\mathrm{Br} J$ Urol 1995;76:213-5.

16 Musa MT, Faha AH, el-Arabi YE. Aspiration sclerotherapy for hydroceles in the tropics. Br J Urol 1995;76:488-90.

17 Poggensee G, Feldmeier H. Female genital schistosomiasis: facts and hypotheses. Acta Trop 2001;79:193-210.

18 Feldmeier H, Krantz l, Poggensee G. Female genital schistosomiasis as a risk factor for the transmission of HIV. Int J STD AIDS 1994;5:368-72.

19 Poggensee G, Kiwelu I, Weger V, et al. Female genital schistosomiasis of the lower genital tract: prevalence and disease-associated morbidity in Northern Tanzania. J Infect Dis 2000;181:1210-3.

20 Feldmeier H, Daccal RC, Martins MJ, et al. Genital manifestations of schistosomiasis mansoni in women: important but neglected. Mem Inst Oswaldo Cruz 1998;93(Suppl 1):217-33.

21 Qunhua L, Jiawen Z, Bozhao L, et al. Investigation of association between female genital tract diseases and Schistosomiasis japonica infection. Acta Trop 2000;77:179-83.

22 Goldsmith PC, Leslie TA, Sams V, et al. Lesions of schistosomiasis mimicking warts on the vulva. BMJ 1993;307:556-7. 
23 Helling-Giese G, Sjaastad A, Poggensee G, et al. Female genital schistosomiasis (FGS): relationship between gynecological and histopathological findings. Acta Trop 1996;62:257-67.

24 Harouny A, Pedersen H. Pelvo-peritoneal schistosomiasis as a cause of primary infertility. Int J Gynaecol Obstet 1988;27:467-9.

25 Ville $\mathrm{Y}$, Leruez M, Picaud A, et al. Tubal schistosomiasis as a cause of ectopic pregnancy in endemic areas? A report of three cases. Eur J Obstet Gynecol Reprod Biol 1991;42:77-9.

26 Poggensee G, Sahebali S, Van Marck E, et al. The diagnosis of cervical genital schistosomoiasis: comparison of cytological, histopathological and parasitological examination. Am J Trop Med Hyg 2001;65:233-6.

27 Swart PR, van der Merwe JV. Wet-smear diagnosis of genital schistosomiasis. $S$ Afr Med J 1987;72:631-2.

28 Poggensee G, Reimert CM, Nilsson LA, et al. Diagnosis of female genita schistosomiasis by indirect disease markers: determination of eosinophil cationic protein, neopterin and $\lg \mathrm{A}$ in vaginal fluid and swab eluates. Acta Trop 1996;62:269-280.

29 Barlow BA, Meleney HE. A voluntary infection with S haematobium. Am J Trop Med Hyg 1949:29:79-87.

30 McKenna G, Schousboe M, Paltridge G. Subjective change in ejaculate as symptoms of infection with Schistosoma haematobium in travellers. BMJ 1997;315:1000-1.

31 Feldmeier $\mathrm{H}$, Leutscher $\mathrm{P}$, Poggensee $\mathrm{G}$, et al. Male genital schistosomiasis and haemospermia. Trop Med Int Health 1999;4:791-3.

32 Lewis DA, al-Adnani MS, Murphy SM. Altered seminal ejaculate consistency due to schistosomiasis. Br J Urol 1996;78:956-7.

33 Corachan M, Valls ME, Gascon J, et al. Hematospermia: a new etiology of clinical interest. Am J Trop Med Hyg 1994;50:580-4.

34 Vilana R, Corachan M, Gascon J, et al. Schistosomiasis of the male genital tract: transrectal sonographic findings. J Urol 1997;158:1491-3.

35 Githae GM. Testicular schistosomiasis simulating a malignant fumour or tuberculosis. S Afr Med J 1992:81:338.

36 Steinberger RM, Lindsay KG, Alassandri R, et al. Infarction of testicle and Schistosoma mansoni. Urology 1975;5:567-9.

37 Kazzaz BA, Salmo NA. Epididymitis due to Schistosoma haematobium infection. Tropical and Geographical Medicine 1974;26:333-6.

38 Badejo OA, Soyinka F, Laja AO. Ectopic lesion of schistosomiasis of the penis simulating an early carcinoma. Acta Trop 1978;35:263-7.

39 Girgis SM, Wassef NF. Bilharziasis and azoospermia. Arch Androl 1980;5:369-72.

40 Antony SJ, Lopez-Po P. Genital amebiasis: historical perspective of an unusual disease presentation. Urology 1999;54:952-5.

41 Mhlanga BR, Lanoie LO, Norris HJ, et al. Amebiasis complicating carcinomas: a diagnostic dilemma. Am J Trop Med Hyg 1992;46:759-64.

42 Othman NH, Ismail AN. Endometrial amoebiasis. Eur J Obstet Gynecol Reprod Biol 1993;52:135-7.

43 Calore EE, Calore NMP, Cavaliere MJ. Salpingitis due to Entamoeba histolytica. Braz J Infect Dis 2002;6:97-9.

44 Citronberg RJ, Semel JD. Severe vaginal infection with Entamoeba histolytica in a woman who recently returned from Mexico: case report and review. Clin Infect Dis 1995;20:700-2.

45 Mylius RE, Ten Seldam RE. Venereal infection by Entamoeba histolytica in a New Guinea couple. Tropical and Geographical Medicine 1962:14:20-6.

46 Cabello I, Caraballo A, Millan Y. Leishmaniasis in the genital area. Rev Inst Med Trop Sao Paolo 2002;44:105-7.
47 Castro-Coto A, Hidalgo-Hidalgo $\mathrm{H}$, Solano-Aguilar $\mathrm{E}$, et al. Leishmaniasis en organos genitales. Med Cutan Ibero Lat Am 1987;15:145-50.

48 Blickstein I, Dgani R, Lifschitz-Mercer B. Cutaneous leishmaniasis of the vulva. Int J Gunaecol Obstet 1993;42:46-7.

49 Gorse JG, Belshe RB. Male genital tuberculosis: a review of the literature with instructive case reports. Rev Infect Dis 1985;7:51 1-24.

50 Lewis EL. Tuberculosis of the penis: a report of 5 cases and complete review of the literature. J Urol 1946;56:737-45.

51 Lattimer JK, Colmore HP, Sanger G, et al. Transmission of genital tuberculosis from husband to wife via the semen. Am Rev TB Pulm Dis 1954;69:618.

52 Margolis K, Wranz PAB, Kruger TF, et al. Genital tuberculosis at Tygerberg Hospital-prevalence, clinical presentation and diagnosis. S Afr Med J 1992;81:12-15

53 Nogales-Ortiz F, Tarancon I, Nogales FF. The pathology of female genital tuberculosis. A 31-year study of 1436 cases. Obstet Gynecol 1979;53:422-8.

54 Sutherland AM. Postmenopausal tuberculosis of the female genital tract. Obstet Gynecol 1982:59(Suppl):S54-7.

55 Chow TW, Lim BK, Vallipuram S. The masquerades of female pelvic tubercuculosis: case reports and review of literature on clinical presentations and diagnosis. J Obstet Gynaecol Res 2002;28:203-10.

56 Baum SE, Dooley DP, Wright J, et al. Diagnosis of culture-negative female genital tract tuberculosis with peritoneal involvement by polymerase chain reaction. J Reprod Med 2001;46:929-32.

57 Tripathy SN, Tripathy SN. Infertility and pregnancy outcome in female genital tuberculosis. Int J Gynecol Obstet 2002;76:159-63.

58 Lamba $\mathrm{H}$, Byrne M, Goldin R, et al. Tuberculosis of the cervix: case presentation and a review of the literature. Sex Transm Infect 2002:78:62-3.

59 Pardini I. Sulla tuberculosi primitiva della vulva. Rivista italiana di Ginecologia 1947;32:207.

60 Akhtar M, Ali MA, Mackey DM. Lepromatous leprosy presenting as orchitis. Am J Clin Pathol 1980;73:72-5.

61 Saporta L, Yuksel A. Androgenic status in patients with lepromatous leprosy. Br J Urol 1994;74:221-4.

62 Ghorpade A, Ramanam C. Primary penile tuberculoid leprosy. Indian J Lepr 2000:72:499-500.

63 Parikh DA, Parikh AC, Ganapati R. Penile and scrotal lesions in leprosy: case reports. Lepr Rev 1989;60:303-5.

64 World Health Organization. WHO expert committee on leprosy. Sixth report. Genera: WHO, 1988, Tech Rep Ser 768.

65 Kadikoylu G, Tuncer G, Bolaman Z, et al. Brucellar orchitis in Innerwest Anatolia Region of Turkey. A report of 12 cases. Urol Int 2002;69:33-5.

66 Mantur BG, Mangalgi SS, Mulimani M. Brucella melitensis-a sexually transmitted agent? Lancet 1996;347:1763.

67 Navarro-Martínez A, Solera J, Corredoira, et al. Epididymoorchitis due to Brucella mellitensis: a retrospective study of 59 patients. Clin Infect Dis 2001;33:2017-22.

68 Montejo JM, Alberola I, Glez-Zarate P, et al. Open, randomized therapuetic trial of six antimicrobial regimens in the treatment of human brucellosis. Clin Infect Dis 1993;16:671-6.

69 Malhotra HK, Wig NN. Dhat syndrome: a culture-based sex neurosis of the orient. Arch Sex Behav 1975;4:519-28.

70 Mumford DB. The Dhat syndrome: a culturally determined symptom of depression? Acta Psychiatr Scand 1996;94:163-7.

71 Jilek W, Jilek-Aall L. Massen hysterie mit Koro-Symptomatik in Thailand. Schweiz Archiv Neurol Neurochir Psychiatr 1977;120:257-9. 